\title{
PENGARUH POLA PERMISIF ORANGTUA TERHADAP PEMBENTUKAN KEPRIBADIAN ANAK
}

\author{
Inggriani Ngongo \\ Sekolah Tinggi Agama Kristen Terpadu Pesat Salatiga \\ inggiinggri9@gmail.com
}

\begin{abstract}
ABSTRACK
Children are entrusted by God. Parents are obliged to treat children in line with God's will that has been entrusted, not the wishes of the parents. Allah's intention to entrust children is that parents can learn to be good carers for their children. Parents must realize that the child is entrusted by Allah. Allah gives trust to parents to look after, care for, guide, direct, and treat children well, without allowing children to do everything without guidance and direction from parents. The purpose of this is to find out about the application of parental permissive patterns for children. Aspects that are applied permissive parenting. The impact of permissive parenting on the formation of a child's personality. In this paper, using library research methods or literature studies. Library research limits its activities to library collection materials without requiring field research. The results of the literature research show that parents know the best ways and styles of parenting for children. If parents give freedom for children to act according to their wishes, parents must also provide and establish rules that are accompanied by commitments with children. So that the child has a well-formed personality that can make the child able to determine the best for his life in the future.
\end{abstract}

Key Words : Parents Permissive Pattern; Personality; Child

\begin{abstract}
ABSTRAK
Anak adalah titipan Allah. Orangtua wajib memperlakukan anak sejalan dengan kehendak Tuhan yang menitipkan, bukan kemauan orangtua. Maksud Allah menitipkan anak yaitu agar orangtua dapat belajar menjadi pengasuh yang baik bagi anak. Orangtua harus menyadari bahwa anak itu adalah titipan Allah. Allah memberikan kepercayaan kepada orangtua untuk menjaga, merawat, membimbing, mengarahkan, serta memperlakukan anak dengan baik, tanpa membiarkan anak melakukan segala sesuatu tanpa bimbingan dan arahan dari orangtua. Tujuan penelitian yaitu, untuk mengetahui penerapan pola permisif orangtua bagi anak. Aspek-aspek yang diterapkan pola asuh permisif. Dampak pola asuh permisif bagi pembentukan kepribadian anak. Dalam penulisan ini, menggunakan metode penelitian pustaka atau studi literatur. Riset pustaka membatasi kegiatannya hanya pada bahan-bahan koleksi perpustakaan saja tanpa memerlukan riset lapangan. Hasil dari Penelitian kepustakaan yaitu orangtua mengetahui cara dan gaya pengasuhan yang terbaik untuk anak. Jika orangtua memberikan kebebasan untuk anak bertindak sesuai dengan keinginannya, orangtua juga harus memberikan dan menetapkan peraturan-peraturan yang disertai komitmen dengan anak. Sehingga anak memiliki kepribadian yang terbentuk dengan baik. Yang dapat membuat anak mampu menentukan yang terbaik untuk kehidupannya ke depan.
\end{abstract}


Kata Kunci : Pola Permisif Orangtua; Kepribadian; Anak.

\section{PENDAHULUAN}

Menurut UU perlindungan Anak No. 35 Tahun 2014 Pasal 1 yang dimaksud anak adalah seseorang yang belum berusia 18 tahun, termasuk anak yang masih dalam kandungan. ${ }^{1}$ Anak adalah titipan Allah. Yang Artinya orangtua wajib memperlakukan anak sejalan dengan kehendak Tuhan yang menitipkan, bukan kemauan orangtua. Maksud Allah menitipkan anak yaitu agar orangtua dapat belajar menjadi pengasuh yang baik bagi anak. Anak-anak diibarat seperti anak panah dan Allah adalah sang pemanahnya, sedangkan orangtua adalah busur panahnya. $^{2}$ Anak-anak adalah desain Tuhan untuk memenuhi semua visi dan rencana-Nya, secara pribadi anak-anak itu menjadi target dari seteru Allah. Jika anakanak dihancurkan, maka semua rencana Allah yang telah ditetapkan tidak akan terjadi, karena pertempuran dengan seteru Allah mengacaukan desain Allah. 3 Berkaitan dengan hal di atas. Alkitab telah menuliskan bahwa anak-anak itu adalah milik pusaka Tuhan, anak adalah upah dari Tuhan, anak adalah anak-anak panah di tangan pahlawan. Dimana, orangtua adalah

\footnotetext{
${ }^{1}$ Tim KTAK, Teologi Anak (Jakarta Pusat: Perkantas Jatim, 2018).

${ }^{2}$ Ichwan S. Chahyadi, 3D Of Parenting (Bandung:

PT. VISI ANUGERAH INDONESIA, 2018).
}

pahlawan yang mengarahkan anak untuk menjadi anak-anak yang melesat, memiliki arah, tujuan, sasaran hidup yang tepat dalam hidup masa mudanya (Mazmur 127: 3-4).

Dalam hal ini, orangtua harus menyadari bahwa anak itu adalah titipan Allah. Yang artinya, Allah memberikan kepercayaan kepada orangtua untuk menjaga, merawat, membimbing, mengarahkan, serta memperlakukan mereka dengan baik, tanpa melalaikan atau membiarkan mereka melakukan segala sesuatu tanpa bimbingan dan arahan dari orangtua. Oleh karena itu, pergunakanlah sebaik-baiknya kepercayaan yang Allah berikan yaitu menjadi orangtua yang baik. Memperhatikan dengan baik pola pengasuhan yang digunakan dan seperti apa dampaknya bagi pembentukan kepribadian anak.

Gaya pengasuhan Permisif merupakan gaya pengasuhan orangtua terhadap anak dengan tujuan membentuk kepribadian anak melalui metode pemberian pengawasan yang terlalu bebas dan memberikan keleluasaan bagi anak

\footnotetext{
${ }^{3}$ Tri Budiardjo, Merajut Teologi Anak (Yogyakarta: ANDI, 2019).
} 
untuk mengerjakan suatu hal tanpa adanya pengawasan penuh dari orangtua. ${ }^{4}$ Pola asuh permisif adalah untuk segala sesuatu orangtua mengijinkan anak untuk melakukan apa saja. Orangtua memberikan kelonggaran pada anak untuk bertindak berdasarkan kemauannya sendiri. Pola asuh orang tua permisif bertindak sangat santai, memberi kelonggaran pada anak tanpa disertai peraturan-peraturan yang wajib dipatuhi oleh anak. ${ }^{5}$

Dengan menggunakan pola pengasuhan permisif, hubungan atau kasih sayang orangtua dan anak Anak-anak lebih terasa dekat. Namun, tidak berdampak baik bagi pembentukan kepribadaian anak .

\section{METODE PENELITIAN}

Dalam penulisan ini, akan menggunakan metode penelitian pustaka atau studi literatur. Dr. Amir Hamzah, M.A. dalam bukunya yang berjudul Metode Penelitian Kepustakaan Library Research mengatakan bahwa penelitian kepustakaan adalah cara kerja ilmiah yang tergolong dalam jenis penelitian kualitatif. Riset pustaka membatasi kegiatannya hanya pada bahan-bahan koleksi perpustakaan saja tanpa memerlukan riset lapangan. Tujuan penelitian yaitu, Pertama, untuk mendapatkan deskripsi

\footnotetext{
${ }^{4}$ Tridhonanto and Beranda Agency, Mengembangkan Pola Asuh Demokratis (Jakarta: PT Elex Media Komputindo, 2014).
}

tentang penerapan pola asuh permisif orangtua bagi anak. Kedua, untuk mendapatkan deskripsi tentang aspekaspek-aspek yang diterapkan pola asuh permisif. Ketiga, untuk mendapatkan deskripsi tentang dampak pola asuh permisif bagi pembentukan kepribadian anak.

\section{HASIL DAN PEMBAHASAN}

\section{Pola Permisif Orang Tua}

\section{Penerapan Pola Asuh Permisif Orang}

Tua Bagi Anak.

Setiap orangtua mempunyai cara tersendiri di dalam membimbing dan mengasuh anak-anak. Tergantung orangtua, mana yang terbaik untuk anak. Namun, tidak sedikit juga orangtua yang salah mendidik anak. Mungkin, orangtua berpikir bahwa inilah cara yang paling cocok, paling bagus untuk membentuk kehidupan anak. Tanpa memikirkan dampak atau pengaruh yang akan terjadi pada anak ke depannya. Salah satu pola pengasuhan yang biasa di gunakan, bahkan tidak sedikit dari sekian banyak orangtua yang menggunakan pola asuh ini, yaitu Gaya pengasuhan permisif.

"Gaya Pengasuhan permisif adalah orangtua menggunakan cara dengan tidak memberikan batasan dan biasanya anak

\footnotetext{
5 Tustik Hidayati, Lis Hanifah, and Yessy Nur Endah Sari, Pendampingan Gizi Pada Balita (Yogyakarta: CV BUDI UTAMA, 2019).
} 
akan tumbuh tanpa arahan (Dian dan Hizkia, 2019). “

Pola asuh permisif adalah pola asuh orangtua yang dicirikan dengan tidak membimbing anak dan menyetujui segala tingkah laku anak termasuk keingingnankeinginan yang sifatnya segera dan tidak menggunakan hukuman (Budisetyani, 2014)." ${ }^{6}$ Bahwa dengan gaya pengasuhan semacam ini, anak akan menjadi pribadai yang berlaku dan bertindak sesuka hatinya. Baik atau tidak yang penting orangtua tidak melarang. Sementara itu Hurlock (1976) menyatakan bahwa pola asuh permisif bercirikan adanya kontrol yang kurang, orangtua bersikap longgar dan bebas, dan bimbingan terhadap anak tidak banyak dilakukan. Selanjutnya Bowerman dalam Conger (1975) mengatakan bahwa bentuk pola asuh permisif adalah semua keputusan dibuat di mana anak justru lebih banyak mempunyai peranan dari pada orangtuanya. Iman Barnabib (1986) pola asuh orangtua yang permisif kurang tegas dalam menerapkan peraturan-peraturan yang ada, dan anak diberikan kesempatan sebebas-bebasnya untuk berbuat dan memenuhin keinginannya. ${ }^{7}$

Berdasarkan uraian di atas maka dapat disimpulkan bahwa Gaya atau Pola Pengasuhan Permisif adalah jenis pola

\footnotetext{
${ }^{6}$ Maulidya Ulfah, Digital Parenting (Jawa Barat: EDU PUBLISHER, 2020).
}

pengasuhan yang memberikan kebebasan penuh pada anak untuk bertindak dan melakukan segala sesuatu sesuai dengan keinginannya sendiri,tanpa adanya pengawasan atau kontrol dari orangtua yang disertai dengan norma-norma atau peraturan-peraturan dari orangtua yang wajib untuk dipatuhi oleh anak dalam melakukan sesuatu yang anak inginkan.

Dalam hal ini, sangat terlihat jelas bahwa ada kelalaian orangtua di dalam mendidik dan membimbing anak. Memang, gaya pengasuhan semacam ini membuat kasih sayang orangtua dan anak lebih terasa. Namun, anak tidak akan menghargai keputusan maupun arahan orangtuanya. Karena anak akan berpikir bahwa segala sesuatu yang dia lakukan tidak perlu orangtua campur tangan di dalamnya. Sebab, anak sudah terbiasa dengan gaya orangtuanya yang tidak mau tahu atau tidak mempedulikan hal-hal yang dilakukan oleh anak. Gaya pengasuhan yang terlalu memanjakan anak ini, akan membuat anak sulit membedakan hal terbaik untuk dirinya dan hal yang dapat menghancurkan hidupnya. Karena orangtua tidak pernah memberitahukan kepada anak, hal yang boleh anak lakukan yang dapat membuat anak sukses dan hal

\footnotetext{
${ }^{7}$ Ahmad Susanto, Bimbingan Dan Konseling (Jakarta: PRENADAMEDIA GROUP, 2015).
} 
yang tidak boleh anak lakukan yang dapat menghancurkan hidup anak.

Orangtua yang menggunakan gaya pengasuhan permisif akan memiliki sifat lalai dalam menyampaikan kepada anak mengenai peraturan-peraturan yang harus dipatuhi oleh anak. tidak menetapkan saat memberikan disiplin, akan tetapi lumayan dekat dengan anak.

Dalam pola pengasuhan permisif ini terdapat kekurangan orangtua di dalam membatasi dan tidak adanya sanksi yang diberikan pada anak, saat anak melakukan kesalahan. Sehingga hal ini dapat membuat anak melakukan lagi kesalahan yang sama.

Maka dari itu, orangtua harus tahu cara dan gaya pengasuhan yang terbaik untuk anak. Jika orangtua memberikan kebebasan untuk anak bertindak sesuai dengan keinginannya, orangtua juga harus memberikan dan menetapkan peraturanperaturan yang disertai komitmen dengan anak. Sehingga anak memiliki kepribadian yang terbentuk dengan baik. Yang mampu membuat anak mampu menentukan yang terbaik untuk kehidupannya ke depan.
Aspek-Aspek yang Diterapkan Pola asuh Permisif

1. Orangtua tidak peduli terhadap pertemanan atau persahabatan anaknya.

2. Orangtua kurang memberikan perhatian terhadap kebutuhan anaknya. Jarang sekali melakukan dialog terlebih untuk mengeluh dan meminta pertimbangan.

3. Orangtua tidak peduli terhadap pergaulan anaknya dan tidak pernah menentukan norma-norma yang harus diperhatikan dalam bertindak.

4. Orangtua tidak peduli dengan masalah yang dihadapi oleh anaknya.

5. Orangtua tidak peduli terhadap kegiatan kelompok yang diikuti anaknya.

6. Orangtua tidak anaknya bertanggung jawab atai tidak atas tindakan yang dilakukannya. ${ }^{8}$

Melihat aspek-aspek di atas, betapa sangat menyedihkan orangtua tidak menjalankan peran dan tanggung jawab dengan baik dalam kehidupan anak

\footnotetext{
${ }^{8}$ Alwisol, Psikologi Kepribadian (Malang: Universitas Muhammadiyah Malang, 2018).
} 


\section{Kepribadian Anak}

Kepribadian adalah bawaan atau kesukaan yang dipunyai masing-masing individu dalam menanggapi dan membangun hubungan dengan individu lain. Masing-masing individu tidak tidak memiliki kepribadaian yang sama. Begitu juga dengan anak-anak. Saat anak masih kecil, mungkin tidak tampak jelas kepribadiannya, namun akan terlihat jelas sejalan dengan perkembangan anak. ${ }^{9}$ Kepribadian adalah suatu gabungan dimensi jiwa dan fisik, yang mengakibatkan adanya gabungan dalam perilaku dan perbuatan seseorang. Kepribadian selalu diibaratkan seperti arah segala perilaku seorang individu terhadap tiap-tiap fase perkembangannya. ${ }^{10}$ Kepribadian (Personality) merupakan karakter dan perilaku khusus individu yang membedahkannya dengan individu lain. Kepribadian bukanlah sesuatu yang stagnan atau mati tetapi kepribadian mempunyai bawaan-bawaan yang bergerak atau aktif yang disebut dinamika kepribadian. Dinamika kepribadian ini bertumbuh cepat dalam diri anak-anak (masa kanak-kanak) karena memang diri mereka belum dewasa, yang berarti mereka

\footnotetext{
${ }^{9}$ Ichwan S. Chahyadi, 3D Of Parenting.

${ }^{10}$ Singgih D. Gunarsa and Yulia Singgih D. Gunarsa, Psikologi Untuk Membimbing (Jakarta: PT BPK Gunung Mulia, 2012).
}

masih dalam tahap pembentukan kepribadian. ${ }^{11}$

Sementara Maddy dan Burt mendefinisikan Kpribadaian sebagai seperangkat karakteristik dan kecenderungan yang stabil, yang menetukan keumuman dan perbedaan tingkah laku psikologik (berpikir, merasa, dan gerakan) dari seseorang dalam waktu yang panjang da tidak dapat dipahami secara sederhana sebagai hasil dari tekanan sosial dan tekanan biologik saat itu. Selanjutnya Kepribadaian menurut Phares adalah pola khas dai fikiran, perasaan, dan tingkah laku yang membedakan orang satu dengan yang lain dan tidak berubah lintas waktu dan situasi. ${ }^{12}$

Berdasarkan uraian di atas maka dapat disimpulkan bahwa kepribadaian anak adalah sikap, bawaan, karakteristik seseorang yang terus menerus mengalami pembentukan, tidak stagnan tetapi terus bergerak atau aktif dan bertumbuh sangat cepat dalam diri anak. karena, anak-anak itu belum dewasa. mereka masih dalam fase pembentukan kepribadian.

Terbentuknya kepribadian anak tergantung pada pola pengasuhan yang orangtua gunakan. Karena di usia anak yang masih terlalu kecil, sangat mudah

\footnotetext{
${ }^{11}$ David Chairilsyah, "Pembentukan Kepribadian Positif Anak Sejak Usia Dini," Educhild 1, no. 1 (2012).

${ }^{12}$ Alwisol, Psikologi Kepribadian.
} 
dipengaruhi oleh banyak hal. baik itu hal yang baik mau pun hal yang buruk sekali pun.

Jadi, ketika kelak nanti anak memiliki karakter yang tidak baik. Orangtua perlu juga mengoreksi atau mengevaluasi metode-metode yang orangtua gunakan selama ini dalam mendidik, membimbing, dan membesarkan anak. Sehingga, tidak selalu anak yang disalahkan ketika ada masalah yang terjadi pada diri anak.

\section{Dampak yang Ditimbulkan dari Pola} Asuh Permisif

1. Anak bertindak spontan dan kasar.

2. Suka membantah.

3. Memiliki kepercayaan diri dan pengelolaan diri yang kurang.

4. Suka memerintah

5. Memiliki arah hidup yang tidak pasti.

6. Kemampuan dibawa rata-rata. 13
Dampak-dampak di atas juga tidak hanya merugikan diri anak sendiri, tetapi juga dapat merugikan orang lain, baik orangtuanya, teman sebaya, dan lingkungannya.

\section{KESIMPULAN}

Berdasarkan hasil penelitian kepustakaan, maka dapat disimpulkan bahwa penerapan pola asuh permisif orangtua bagi anak yaitu orangtua terlalu memberikan kebebasan penuh anak untuk bertindak. Orangtua juga tidak hanya sekedar menerapkan pola asuh permisif , tetapi juga dapat mengetahui dampak dari setiap aspek yang diterapkan oleh pola asuh permisif yang terhadap kepribadian anak. Dengan orangtua mengetahui dampak dari pola asuh permisif, maka orangtua dapat mencari cara menangani dampak yang dihasilkan. Sehingga kepribadian anak dapat berkembang dengan baik sesuai dengan yang diharapkan. 


\section{DAFTAR PUSTAKA}

Alwisol. Psikologi Kepribadian. Malang: Universitas Muhammadiyah Malang, 2018.

Chairilsyah, David. "Pembentukan Kepribadian Positif Anak Sejak Usia Dini." Educhild 1, no. 1 (2012).

Gunarsa, Singgih D., and Yulia Singgih D. Gunarsa. Psikologi Untuk Membimbing. Jakarta: PT BPK Gunung Mulia, 2012.

Hidayati, Tustik, Lis Hanifah, and Yessy Nur Endah Sari. Pendampingan Gizi Pada Balita. Yogyakarta: CV BUDI UTAMA, 2019.

Ichwan S. Chahyadi. 3D Of Parenting. Bandung: PT. VISI ANUGERAH INDONESIA, 2018.

Susanto, Ahmad. Bimbingan Dan Konseling. Jakarta: PRENADAMEDIA GROUP, 2015.

Tim KTAK. Teologi Anak. Jakarta Pusat: Perkantas Jatim, 2018.

Tri Budiardjo. Merajut Teologi Anak. Yogyakarta: ANDI, 2019.

Tridhonanto, and Beranda Agency. Mengembangkan Pola Asuh Demokratis. Jakarta: PT Elex Media Komputindo, 2014.
Ulfah, Maulidya. Digital Parenting. Jawa Barat: EDU PUBLISHER, 2020. 